\title{
Effects of CYP3A5 genetic polymorphism and smoking on the prognosis of non-small-cell lung cancer
}

\author{
Li-Peng Jiang' \\ Zhi-Tu Zhu ${ }^{2}$ \\ Chun-Yan $\mathrm{He}^{3}$ \\ 'Department of Radiation Oncology, \\ ${ }^{2}$ Department of Oncology, First \\ Affiliated Hospital of Liaoning \\ Medical University, ${ }^{3}$ Department \\ of Prosthodontics, Second Affiliated \\ Hospital of Liaoning Medical \\ University, Jinzhou, People's Republic \\ of China
}

This article was published in the following Dove Press journal:

OncoTargets and Therapy

14 March 2016

Number of times this article has been viewed

Objective: We aimed to explore the impacts of the rs 776746 polymorphism in the CYP $3 A 5$ gene and smoking on the prognosis of non-small-cell lung cancer (NSCLC).

Materials and methods: Our study enrolled 104 early NSCLC patients undergoing surgery and 107 advanced NSCLC patients undergoing chemotherapy, hospitalized between December 2009 and December 2012 at the First Affiliated Hospital of Liaoning Medical University. All subjects with complete follow-up data were pathologically diagnosed. The rs776746 polymorphism and different genotypes $(* 1 / * 1, * 1 / * 3$, and $* 3 / * 3)$ were identified by polymerase chain-reaction restriction fragment-length polymorphism.

Results: Clinical response to chemotherapy in NSCLC patients with $* 1 / * 1+* 1 / * 3$ genotypes were significantly worse than in those with the * $3 / * 3$ genotype $(17.78 \%$ vs $56.45 \%, P<0.001)$, and after Bonferroni adjustment, the differences still showed significance $\left(P_{\mathrm{c}}<0.01\right)$. The mortality risk of NSCLC patients undergoing chemotherapy with the *3/*3 genotype was 0.617 times those with $* 1 / * 1+* 1 / * 3$ genotypes (relative risk [RR] $0.617,95 \%$ confidence interval [CI] $0.402-0.948 ; P=0.028$ ), while the mortality risk of smoking patients was 1.743 times greater than that of nonsmoker patients (RR $1.743,95 \%$ CI 1.133-2.679; $P=0.042$ ). Furthermore, a 3.087-fold mortality risk was found in NSCLC patients undergoing surgery with the *3/*3 genotype compared with those with $* 1 / * 1+* 1 / * 3$ genotypes (RR 3.087, 95\% CI 1.197-7.961; $P=0.020)$. In NSCLC patients undergoing surgery, the mortality risk of smokers was 1.896 times greater than nonsmokers (RR 1.896, 95\% CI 1.040-3.455; $P=0.037$ ).

Conclusion: Our study demonstrated that the CYP3A5 rs776746 polymorphism and smoking may influence the prognosis of NSCLC patients undergoing chemotherapy and surgery.

Keywords: cytochrome P450 3A5, non-small-cell lung cancer, smoking, polymorphism, prognosis, chemotherapy, surgery

\section{Introduction}

With its high incidence and mortality, lung cancer has been one of the most frequent malignant cancers worldwide for several decades. ${ }^{1}$ In 2008 , more than 1.6 million individuals were diagnosed with lung cancer, which comprised $13 \%$ of all newly diagnosed cancer. ${ }^{2}$ Of the subtypes of lung cancer, non-small-cell lung cancer (NSCLC) which consists of two main histological types - squamous cell carcinoma and adenocarcinoma - accounts for approximately $85 \%$ of new cases. ${ }^{3,4}$ The geographic epidemic of lung cancer has been caused by cigarette smoking to some extent, and approximate $80 \%-90 \%$ of lung cancers, predominantly NSCLC, are likely attributed to cigarette smoking. ${ }^{5}$ Lung cancer incidence is increasing in the People's Republic of China and several Asian and African countries in which the prevalence of tobacco
Correspondence: Zhi-Tu Zhu Department of Oncology, First Affiliated Hospital of Liaoning Medical University, 2 Renmin Street, Jinzhou, Liaoning 121000 , People's Republic of China Tel +86 18041602727

Email zhuzhitu0806@I63.com (c) License. The full terms of the License are available at http://creativecommons.org/licenses/lyy-nc/3.0/. Non-commercial uses of the work are permitted without any further permission from Dove Medical Press Limited, provided the work is properly attributed. Permissions beyond the scope of the License are administered by Dove Medical Press Limited. Information on how to request permission may be found at: http://www.dovepress.com/permissions.php 
consumption continues to either increase or remain stable. ${ }^{6}$ Although combined therapies are available for the management and treatment of NSCLC, the majority of patients undergo recurrence because of its high metastasis and invasion. ${ }^{7}$ The 5-year survival rate of NSCLC remains poor, with an estimated rate of only $2.5 \%$ in the advanced stage. ${ }^{8}$ In the early stage of NSCLC, surgery offers a relatively high possibility of cure if a complete resection is conducted, and a 5-year survival rate of approximately $75 \%$ might be expected, ${ }^{9}$ while for advanced NSCLC patients chemotherapy was recently accepted as the standard treatment strategy. ${ }^{10}$

Although exposure to tobacco smoke is the leading risk factor, the development of NSCLC seems to be the result of a complex interaction between genetic factors and environmental exposures. ${ }^{11}$ Cytochrome P450 (CYP) is involved with heme-containing monooxygenases that feature in drug clearance or biotransformation in vivo, in which the CYP3A enzymes participate in most of the CYP activity and catalyzes oxidation of xenobiotics, including toxins, carcinogens, and drugs. ${ }^{12,13}$ Of all members of the CYP3A subfamily, CYP3A5 represents the majority of the CYP3A activity in the lungs, with high expression in bronchial glands, bronchial and alveolar epithelial cells, and alveolar macrophages. ${ }^{14}$ The $C Y P 3 A 5$ gene is located on chromosome $7 \mathrm{p} 21.1$, spanning approximately $32 \mathrm{~kb}$ in length within the $C Y P 3 A$ gene cluster. ${ }^{15}$ Using a comparative genomics approach together with sequence-based neutrality testing, Polimanti et al provided evidence of positive selection on the derived allele of the functional rs776746 $\left(C Y P 3 A 5^{*} 3\right)$ in non-African populations and significant correlation of its allelic frequency with distance from the equator. ${ }^{16} \mathrm{~A}$ recent meta-analysis on associations between $C Y P 3 A 5^{*} 3$ and diseases was performed, in which eight studies were conducted in Asian populations and seven studies in Caucasian populations. ${ }^{17}$

The lungs are commonly exposed to all kinds of xenobiotics or inhaled exogenous carcinogens, many of which are likely to correlate with the development of NSCLC. ${ }^{18}$ CYP3A5 plays a crucial role in the oxidative biotransformation of the exogenous carcinogens, including tobacco smoke, the endogenous compounds (such as steroids and progesterone), and pharmaceutical drug metabolism. ${ }^{19}$ However, currently there have been few studies to investigate the direct correlations of the CYP3A5 genetic polymorphism, smoking, and NSCLC. Therefore, we conducted a study that aimed to explore the impacts of the rs 776746 polymorphism in the CYP3A5 gene and smoking on the prognosis of NSCLC.

\section{Materials and methods Subjects}

Our study enrolled 104 early NSCLC patients undergoing surgery and 107 advanced NSCLC patients undergoing chemotherapy, hospitalized between December 2009 and December 2012 in the First Affiliated Hospital of Liaoning Medical University. All patients had measurable tumor focuses by computed tomography and showed normal results in routine blood tests, liver and kidney function, and electrocardiography. Patients with clinical metastasis and preoperative chemotherapy or radiotherapy were excluded from the current study. No patients were related. Peripheral venous blood $(5 \mathrm{~mL})$ was obtained from each subject, followed by anticoagulation using ethylenediaminetetraacetic acid. Then, the blood samples were stored inside a refrigerator at $-80^{\circ} \mathrm{C}$. This study was approved by the ethics committee of the First Affiliated Hospital of Liaoning Medical University. All eligible patients provided written informed consent, and this study was conducted on the basis of ethical principles stated in the Declaration of Helsinki. ${ }^{20}$

\section{SNP detection}

DNA was extracted with a Wizard DNA kit (Promega Corporation, Fitchburg, WI, USA). The purity of DNA samples was determined by ultraviolet spectrophotometry with with optical density at $260 \mathrm{~nm}\left(\mathrm{OD}_{260}\right) / \mathrm{OD}_{280}$ of more than 1.7 , which was qualified for polymerase chain reaction (PCR) amplification and restriction-enzyme reaction. Before the $\mathrm{PCR}$ was performed, the DNA sample was stored at $-20^{\circ} \mathrm{C}$. The rs 776746 polymorphism in the CYP $3 A 5$ gene was identified by PCR restriction fragmentlength polymorphism in a volume of $50 \mu \mathrm{L}$ containing $0.05 \mathrm{U} / \mu \mathrm{L}$ Taq DNA polymerase, $4 \mathrm{mmol} / \mathrm{L} \mathrm{MgCl}_{2}, 0.4 \mathrm{mmol} / \mathrm{L}$ each of the dNTPs (dATP, dCTP, dGTP, and dTTP), $0.4 \mu \mathrm{mol} / \mathrm{L}$ of forward primer, $0.4 \mu \mathrm{mol} / \mathrm{L}$ of reverse primer, 2 ng of template DNA, and double-distilled water. All PCR reactions were carried out as follows: predenaturation at $94^{\circ} \mathrm{C}$ for 5 minutes, denaturation at $94^{\circ} \mathrm{C}$ for 30 seconds, annealing at $55^{\circ} \mathrm{C}$ for 30 seconds, extension at $72^{\circ} \mathrm{C}$ for 1 minute, with a total of 35 cycles, followed by the final extension at $72^{\circ} \mathrm{C}$ for 7 minutes. The primers used in the PCR were synthesized by Invitrogen products (Thermo Fisher Scientific, Waltham, MA, USA), and were used as follows: forward, 5'-CATCAGTTAGTAGACAGATGA- $3^{\prime}$ and reverse, 5'-GGTCCAAACAGGGAAGAAATA-3'. PCR amplification products $(20 \mu \mathrm{L})$ were digested with Dde I enzyme, followed by 4 hours of incubation at $35^{\circ} \mathrm{C}$. The $2 \%$ agarose gel electrophoresis was carried out at $100 \mathrm{mV}$ for 40 minutes for observation, and the image was recorded. 


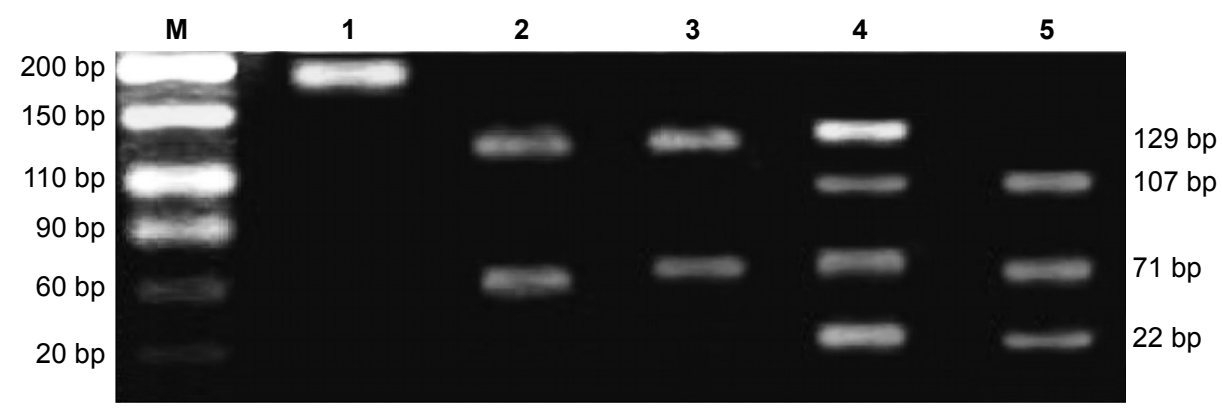

Figure I Electrophoretogram of polymerase chain reaction (PCR) products after enzyme digestion.

Notes: M, marker; lane I, PCR products (200 bP); lanes 2 and 3, CYP3A5*I/*I genotype; lane 4, CYP3A5*I/*3 genotype; lane 5, CYP3A5*3/*3 genotype.

After enzyme digestion, $129 \mathrm{bp}$ and $71 \mathrm{bp}$ existed in the wild-type *1/*1 of the CYP $3 A 5$ gene; $129 \mathrm{bp}, 107 \mathrm{bp}, 71 \mathrm{bp}$, and $22 \mathrm{bp}$ in the heterozygous *1/*3; and $107 \mathrm{bp}, 71 \mathrm{bp}$, and $22 \mathrm{bp}$ in the mutant $* 3 / * 3$. The electrophoretogram of PCR products after enzyme digestion is presented in Figure 1.

\section{Data collection}

Clinical data of the patients were recorded, including admission number, name, sex, age, address, telephone, diagnosis, histological type, staging (TNM [tumor, node, metastasis] or I/II/III/IV), smoking status, Eastern Cooperative Oncology Group (ECOG) performance status (PS) score, the presence or absence of measurable tumor focus, operation situation, radiotherapy history, chemotherapy plan after preliminary diagnosis, chemotherapy-effective rate after preliminary diagnosis, operation date, date of death, patients' condition, and time of metastasis. Patients receiving chemotherapy were all given paclitaxel-based chemotherapy with $135 \mathrm{mg} / \mathrm{m}^{2}$ of paclitaxel per day, the short-term effects of which were analyzed every two cycles according to the Response Evaluation Criteria in Solid Tumors, including complete response, partial response, stable disease, and progressive disease. ${ }^{21}$ Time of assessment for patients was in complete agreement, and effective rate of chemotherapy $=$ number of (complete response patients + partial response patients)/all patients $\times 100 \%$.

\section{Follow-up}

The overall survival and prognosis of patients were followed up every 6 months by telephone between December 2009 and December 2013, with death as an outcome event. Lost cases were defined as patients undergoing one chemotherapy treatment, which were lost to follow-up, and all were out of statistical analysis. Every investigator was trained by the Teaching and Research Section of the First Affiliated Hospital of Liaoning Medical University.

\section{Statistical analysis}

Statistical analysis was performed in SPSS 18.0 software (SPSS Inc., Chicago, IL, USA). Hardy-Weinberg equilibrium was used to test the genotype distribution of the CYP3A5 gene; the $\chi^{2}$ test to analyze the correlations between different genotypes and the clinical outcomes of NSCLC patients undergoing chemotherapy or surgery, which was further adjusted using Bonferroni correction with $P_{\mathrm{c}}<0.05$ considered as statistical significance; Kaplan-Meier (logrank test) to evaluate the risk factors of survival in NSCLC patients; and odds ratio (OR) with $95 \%$ confidence interval (CI) in the logistic regression model to calculate relative risk (RR). All statistical examinations were two-sided, with statistical significance taken as $P<0.05$.

\section{Results \\ Baseline characteristics}

According to case investigation and follow-up, among 231 NSCLC patients, 104 (male 72, female 32) had been given surgery, with a mean age of $59.1 \pm 9.9$ years. Briefly, among 104 patients (smokers 51, nonsmokers 53), 36 had squamous cell carcinoma, 54 had adenocarcinoma, eleven had other types, and three had undifferentiated type, and TNM classification with evidence of 31 of stage I, 49 of stage II, and 24 of stage IIIA. Additionally, 107 (male 73, female 34) had undergone chemotherapy, with a mean age of $58.9 \pm 10.3$ years. These 107 patients (smokers 59, nonsmokers 48) consisted of squamous cell carcinoma $(n=35)$, adenocarcinoma $(\mathrm{n}=55)$, other types $(\mathrm{n}=3)$, and undifferentiated type ( $\mathrm{n}=14)$, and their TNM classification was presented as stage IIIA $(n=5)$, stage IIIB $(n=31)$, and stage IV $(n=71)$. The remaining 20 patients were lost to follow-up not included in our statistical analysis. The baseline characteristics of subjects are summarized in Table 1. There was no significant difference in age, sex, ECOG PS, or smoking status between the surgery group and chemotherapy groups (all $P>0.05$ ), 
Table I Baseline characteristics of patients with non-small-cell lung cancer in the present study

\begin{tabular}{|c|c|c|c|}
\hline $\begin{array}{l}\text { Clinicopathological } \\
\text { parameters }\end{array}$ & $\begin{array}{l}\text { Surgery } \\
(n=104)\end{array}$ & $\begin{array}{l}\text { Chemotherapy } \\
(n=107)\end{array}$ & $P$-value \\
\hline Age (years), mean $\pm S D$ & $59.1 \pm 9.9$ & $58.9 \pm 10.3$ & 0.889 \\
\hline Sex, n (\%) & & & 0.883 \\
\hline Male & $72(69.2)$ & $73(68.2)$ & \\
\hline Female & $32(30.8)$ & $34(31.8)$ & \\
\hline Histological type, n (\%) & & & 0.009 \\
\hline SCC & $36(34.6)$ & $35(32.7)$ & \\
\hline $\mathrm{ADC}$ & $54(51.9)$ & $55(5 \mathrm{I} .4)$ & \\
\hline Other & II (10.6) & $3(2.8)$ & \\
\hline Undifferentiated types & $3(2.9)$ & $14(13.1)$ & \\
\hline TNM, n (\%) & & & $<0.001$ \\
\hline I & $31(29.8)$ & - & \\
\hline ॥ & $49(47.1)$ & - & \\
\hline IIIA & $24(23.1)$ & $5(4.7)$ & \\
\hline IIIB & - & $31(29.0)$ & \\
\hline IV & - & $71(66.4)$ & \\
\hline ECOG PS, n (\%) & & & 0.683 \\
\hline $0-1$ & $102(98.1)$ & $103(96.3)$ & \\
\hline$\geq 2$ & $2(1.9)$ & $4(3.7)$ & \\
\hline Smoking status, n (\%) & & & 0.410 \\
\hline Nonsmoker & $53(51.0)$ & $48(44.9)$ & \\
\hline Smoker & $51(49.0)$ & $59(55.1)$ & \\
\hline
\end{tabular}

Abbreviations: SD, standard deviation; SCC, squamous cell carcinoma; $A D C$, adenocarcinoma; TNM, tumor, node, metastasis; ECOG, Eastern Cooperative Oncology Group; PS, performance status.

while histological type $\left(P=0.009, P_{\mathrm{c}}=0.045\right)$ and TNM staging $\left(P<0.001, P_{\mathrm{c}}<0.01\right)$ exhibited significant differences.

\section{Genotype distribution of CYP3A5 rs776746 polymorphism}

The distributions of CYP3A5 genotypes in NSCLC patients undergoing chemotherapy and surgery are shown in Table 2. There was no difference in the frequencies of CYP $3 A 5$ genotypes and allele between NSCLC patients undergoing chemotherapy and NSCLC patients undergoing surgery (all $P>0.05$ ). The distributions of genotypes in these two groups were not associated with sex, age, histological type, TNM staging, ECOG PS score, or smoking status (all $P>0.05$ ) (Table 3).

Table 2 Distribution of the CYP3A5 rs776746 genotype in patients with non-small-cell lung cancer

\begin{tabular}{lll}
\hline Genotypes & $\begin{array}{l}\text { Surgery } \\
(\mathbf{n}=104)\end{array}$ & $\begin{array}{l}\text { Chemotherapy } \\
(\mathbf{n}=107)\end{array}$ \\
\hline $\begin{array}{l}\text { CYP3A5-6986A/G } \\
\text { CYP3A5*I/*1 }\end{array}$ & $10(9.6)$ & $11(10.3)$ \\
CYP3A5*I*3 & $34(32.7)$ & $34(31.8)$ \\
CYP3A5*3/*3 & $60(57.7)$ & $62(57.9)$ \\
CYP3A5*I & $54(26.0)$ & $56(26.2)$ \\
CYP3A5*3 & $154(74.0)$ & $158(73.8)$ \\
\hline
\end{tabular}

\section{CYP3A5 rs776746 polymorphism and clinical response to chemotherapy in NSCLC patients}

The nonmutated homozygote group $(* 1 / * 1+* 1 / * 3)$ showed a significantly worse clinical response to chemotherapy than the mutated homozygote group $(* 3 / * 3)$, which was statistically significant (17.78\% [eight of 45 ] vs $56.45 \%$ [35 of 62]; $\left.P<0.001, P_{\mathrm{c}}<0.01\right)$. As shown in Table 4, chemotherapy was more effective in the mutated homozygote group $(* 3 / * 3)$ compared with the nonmutated homozygote group $(* 1 / * 1+* 1 / * 3)$ (probability 1 vs $0.167,95 \%$ CI $0.067-0.416$; $\left.P<0.001, P_{\mathrm{c}}<0.01\right)$. Furthermore, our study suggested that clinical response to chemotherapy in stage III patients was notably higher than stage IV patients (OR 3.741, 95\% CI 1.612-8.685; $\left.P=0.003 ; P_{\mathrm{c}}=0.021\right)$, and clinical response to chemotherapy was not relevant to age, sex, histological type, chemotherapy plan, ECOG PS score, or smoking status (all $P>0.05$ ).

\section{CYP3A5 rs776746 polymorphism and overall survival of NSCLC patients undergoing chemotherapy}

A total of 92 NSCLC patients (43.6\%) died, with 33.7 months of median overall survival. Of these 92 dead patients, 59 had undergone chemotherapy, with 18.4 months of median overall survival. The overall survival of patients undergoing chemotherapy with the $* 3 / * 3$ genotype was significantly longer compared with those with $* 1 / * 1+* 1 / * 3(22.6$ [16.4-28.8] vs 14.4 [10.9-17.9], $P=0.042$ ) (Figure 2A). The mortality risk of patients undergoing chemotherapy with the $* 3 / * 3$ genotype was 0.617 times of those with $* 1 / * 1+* 1 / * 3$ ( $95 \%$ CI $0.402-0.948, P=0.028)$ suggesting that the $* 3 / * 3$ genotype reduced the mortality risk for NSCLC patients undergoing chemotherapy. As shown in Figure 2B, the median overall survival of smoking patients was significantly shorter than nonsmoking patients (16.8 [15.0-18.6] vs 24.4 [15.8-33.0], $P=0.042$ ), and smoking increased the mortality risk of NSCLC patients undergoing chemotherapy by 1.743 times (95\% CI 1.133-2.679). After smoking-stratification analysis for the patients undergoing chemotherapy, the overall survival of nonsmoking patients with the $* 3 / * 3$ genotype was significantly longer compared with those with $* 1 / * 1+* 1 / * 3(P=0.010)$, while other stratification analyses based on clinical outcomes did not detect the correlation of genotypes with overall survival (all $P>0.05$ ) (Table 5 and Figure 2C). 
Table 3 The association between the CYP3A5 rs776746 polymorphism and clinicopathological characteristics in non-small-cell lung cancer

\begin{tabular}{|c|c|c|c|c|c|c|c|c|}
\hline \multirow{2}{*}{$\begin{array}{l}\text { Clinicopathological } \\
\text { parameters }\end{array}$} & \multicolumn{3}{|c|}{ Surgery $(n=104)$} & \multirow[t]{2}{*}{$P$-value } & \multicolumn{3}{|c|}{ Chemotherapy $(n=107)$} & \multirow[t]{2}{*}{$P$-value } \\
\hline & $* \mathbf{I} / \mathbf{I}$ & $* 1 / * 3$ & $* 3 / * 3$ & & $* \mathbf{I} / \mathbf{I}$ & $* 1 / * 3$ & $* 3 / * 3$ & \\
\hline Age (years), n (\%) & & & & 0.540 & & & & 0.707 \\
\hline$\geq 55$ & $6(10.5)$ & $16(28.1)$ & $35(61.4)$ & & $6(10.6)$ & $20(35.1)$ & $31(54.4)$ & \\
\hline$<55$ & $4(8.5)$ & $18(38.3)$ & $25(53.2)$ & & $5(10.0)$ & $14(28.0)$ & $31(62.0)$ & \\
\hline Sex, n (\%) & & & & 0.973 & & & & 0.944 \\
\hline Male & $7(9.7)$ & $24(33.3)$ & $4 \mid(56.9)$ & & $8(11.0)$ & $23(31.5)$ & $42(57.5)$ & \\
\hline Female & $3(8.8)$ & $10(29.4)$ & $19(55.9)$ & & $3(8.8)$ & II (32.3) & $20(58.8)$ & \\
\hline Histological type, n (\%) & & & & 0.716 & & & & 0.818 \\
\hline SCC & $3(8.3)$ & $12(33.3)$ & $21(58.3)$ & & $3(8.6)$ & II (3I.4) & $21(62.9)$ & \\
\hline $\mathrm{ADC}$ & $4(7.4)$ & $17(31.5)$ & $33(61.1)$ & & $4(7.2)$ & $17(30.9)$ & $34(61.8)$ & \\
\hline Other & $2(18.2)$ & $4(36.4)$ & $5(45.5)$ & & I (33.3) & I (33.3) & I (33.3) & \\
\hline Undifferentiated types & I (33.3) & I (33.3) & I (33.3) & & $2(14.3)$ & $4(28.6)$ & $8(57.1)$ & \\
\hline TNM, n (\%) & & & & 0.960 & & & & 0.921 \\
\hline 1 & $3(9.7)$ & $9(29.0)$ & $19(61.3)$ & & - & - & - & \\
\hline$\|$ & $5(10.2)$ & $18(36.7)$ & $26(53.1)$ & & - & - & - & \\
\hline IIIA & $2(8.3)$ & $7(29.2)$ & $13(54.2)$ & & I (20.0) & I (20.0) & $3(60.0)$ & \\
\hline IIIB & - & - & - & & $3(9.7)$ & II (35.5) & $17(54.8)$ & \\
\hline IV & - & - & - & & $7(9.9)$ & $22(31.0)$ & $42(59.1)$ & \\
\hline ECOG PS, n (\%) & & & & 0.817 & & & & 0.612 \\
\hline $0-1$ & $10(9.8)$ & $33(32.3)$ & $59(57.8)$ & & $10(9.7)$ & $33(32.0)$ & $60(58.3)$ & \\
\hline$\geq 2$ & $0(0.0)$ & I $(50.0)$ & I $(50.0)$ & & I (25.0) & I $(25.0)$ & $2(50.0)$ & \\
\hline Smoking status, n (\%) & & & & 0.961 & & & & 0.810 \\
\hline Nonsmoking & $5(9.4)$ & $18(34.0)$ & $30(56.6)$ & & $4(8.3)$ & I5 (31.25) & $29(60.4)$ & \\
\hline Smoking & $5(9.8)$ & $16(31.4)$ & $30(58.8)$ & & $7(11.9)$ & $19(32.2)$ & $33(55.9)$ & \\
\hline
\end{tabular}

Abbreviations: SCC, squamous cell carcinoma; ADC, adenocarcinoma; TNM, tumor, node, metastasis; ECOG, Eastern Cooperative Oncology Group; PS, performance status.

Table 4 Relevant factors influencing the efficacy of chemotherapy in advanced non-small-cell lung cancer patients who had undergone chemotherapy, by univariate analysis

\begin{tabular}{|c|c|c|c|c|}
\hline $\begin{array}{l}\text { Clinicopathological } \\
\text { factors }\end{array}$ & $\mathbf{n}$ & $\begin{array}{l}\text { Effective rate of } \\
\text { chemotherapy (\%) }\end{array}$ & OR (95\% Cl) & $P$-value \\
\hline \multicolumn{5}{|l|}{ Age, years } \\
\hline$\geq 55$ & 76 & $39.5(30 / 76)$ & $0.903(0.386-2.11 \mathrm{I})$ & 0.831 \\
\hline$<55$ & 31 & $41.9(|3 / 3|)$ & 1.00 & \\
\hline \multicolumn{5}{|l|}{ Sex } \\
\hline Male & 73 & $38.4(28 / 73)$ & $0.788(0.345-1.799)$ & 0.673 \\
\hline Female & 34 & $44.1(15 / 34)$ & 1.00 & \\
\hline \multicolumn{5}{|l|}{ Histological type } \\
\hline SCC & 35 & $40.0(14 / 35)$ & $0.983(0.278-3.478)$ & 1.000 \\
\hline $\mathrm{ADC}$ & 55 & $40.0(22 / 55)$ & $0.889(0.27|-2.9| 7)$ & 1.000 \\
\hline Other & 3 & $33.3(1 / 3)$ & $0.667(0.048-9.195)$ & 1.000 \\
\hline Undifferentiated types & 14 & $42.9(6 / / 4)$ & 1.00 & \\
\hline \multicolumn{5}{|l|}{ TNM } \\
\hline III & 36 & $61.1(22 / 36)$ & $3.74 \mid(1.6 \mid 2-8.685)$ & 0.003 \\
\hline IV & 71 & $29.6(2 \mid / 7 I)$ & 1.00 & \\
\hline \multicolumn{5}{|l|}{ ECOG PS } \\
\hline $0-1$ & 103 & $39.8(41 / 103)$ & $0.661(0.089-4.885)$ & 1.000 \\
\hline$\geq 2$ & 4 & $50.0(2 / 4)$ & 1.00 & \\
\hline \multicolumn{5}{|l|}{ Smoking status } \\
\hline Nonsmoking & 48 & $39.6(19 / 48)$ & $0.956(0.439-2.079)$ & 1.000 \\
\hline Smoking & 59 & $40.7(24 / 59)$ & 1.00 & \\
\hline \multicolumn{5}{|l|}{ CYP3А5 rs776746 } \\
\hline$* I / * 1+* 1 / * 3$ & 45 & $17.78(8 / 45)$ & $0.167(0.067-0.416)$ & $<0.001$ \\
\hline$* 3 / * 3$ & 62 & $56.45(35 / 62)$ & 1.00 & \\
\hline
\end{tabular}

Abbreviations: OR, odds ratio; $\mathrm{Cl}$, confidence interval; SCC, squamous cell carcinoma; ADC, adenocarcinoma; TNM, tumor, node, metastasis; ECOG, Eastern Cooperative Oncology Group; PS, performance status. 
A

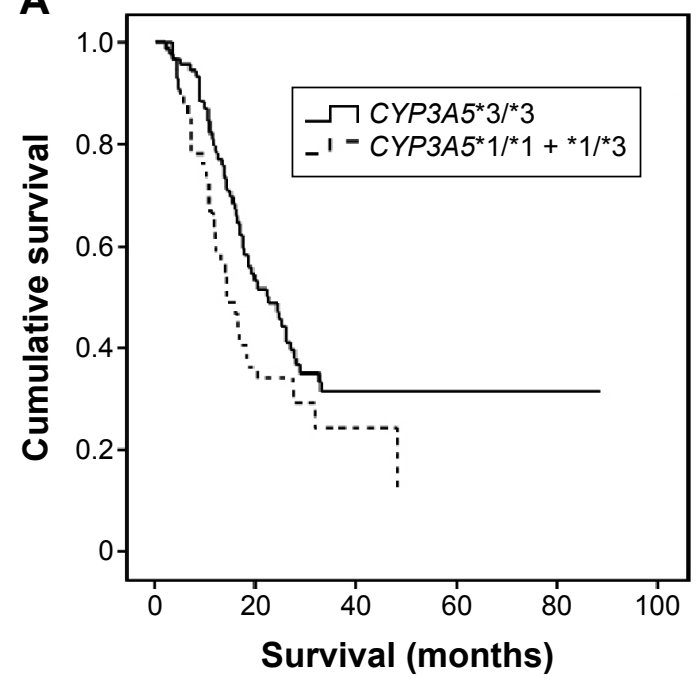

B

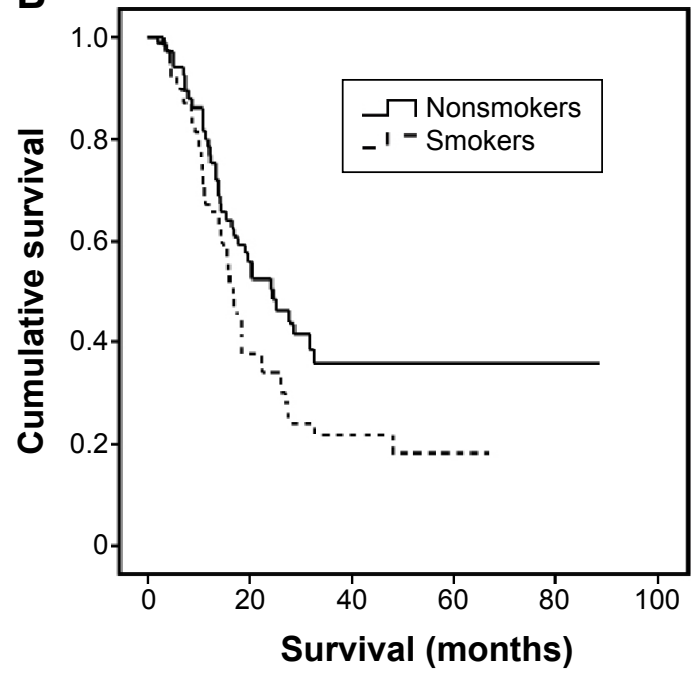

C

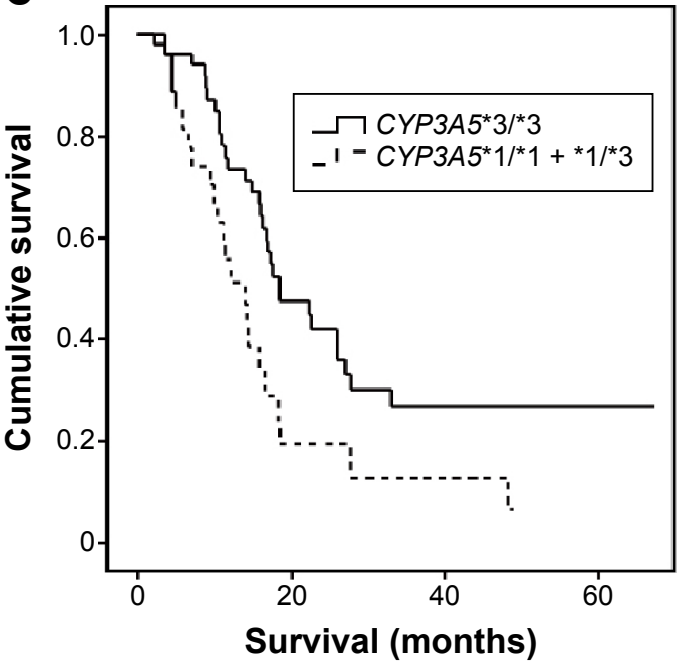

Figure 2 The comparison of overall survival in non-small-cell lung cancer patients undergoing chemotherapy.

Notes: $(\mathbf{A})$ Overall survival in different genotypes $(P=0.042)$; $(\mathbf{B})$ overall survival in smoking and nonsmoking patients $(P=0.042)$; $(\mathbf{C})$ overall survival in different genotypes for nonsmoking patients $(P=0.010)$.

CYP3A5 rs776746 polymorphism and overall survival of NSCLC patients undergoing surgery

Among 92 dead patients, 33 (31.7\%) had surgery, with 57.6 months of median overall survival. NSCLC patients undergoing surgery with the $* 3 / * 3$ genotype had shorter overall survival than those with $* 1 / * 1+* 1 / * 3(16.6[3.3-$ 39.9] vs 57.6 [39.5-75.7], $P=0.009$ ) (Figure 3A), indicating that the $* 3 / * 3$ genotype was a risk factor for these patients, with a mortality risk 3.087 greater than $* 1 / * 1+* 1 / * 3$

Table 5 Association between the CYP3A5 rs776746 polymorphism and overall survival in advanced non-small-cell lung cancer patients who had undergone chemotherapy, by smoking-stratification analysis

\begin{tabular}{|c|c|c|c|c|c|c|}
\hline \multirow{2}{*}{$\begin{array}{l}\text { Stratification } \\
\text { factors }\end{array}$} & \multirow[t]{2}{*}{$\mathbf{n}$} & \multicolumn{2}{|c|}{ MST (months), mean (95\% Cl) } & \multirow[t]{2}{*}{$P$-value } & \multirow[t]{2}{*}{ HR $(95 \% \mathrm{Cl})^{\mathrm{a}}$} & \multirow[t]{2}{*}{$P$-value ${ }^{a}$} \\
\hline & & $* \mathbf{I} / * \mathbf{I}+* \mathbf{I} / * \mathbf{3}$ & $* 3 / * 3$ & & & \\
\hline \multicolumn{7}{|l|}{ Smoking } \\
\hline Yes & 59 & $15.4(9.6-18.4)$ & $18.5(\mid 2.0-25.0)$ & 0.272 & $0.412(0.225-0.754)$ & 0.004 \\
\hline No & 48 & $16.4(9.8-23.0)$ & $27.7(22.7-32.7)$ & 0.010 & & \\
\hline
\end{tabular}

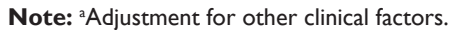

Abbreviations: MST, median survival time; $\mathrm{HR}$, hazard ratio; $\mathrm{Cl}$, confidence interval. 
A

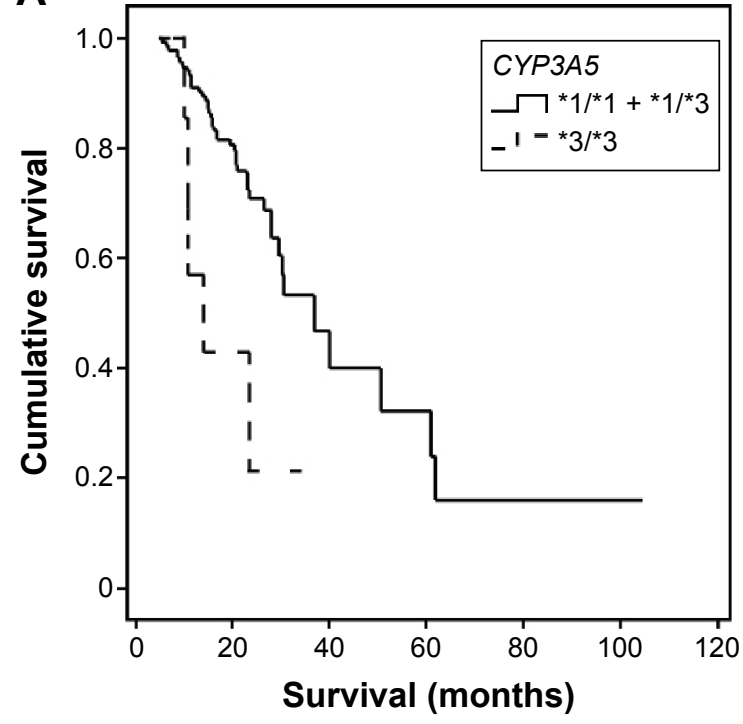

B

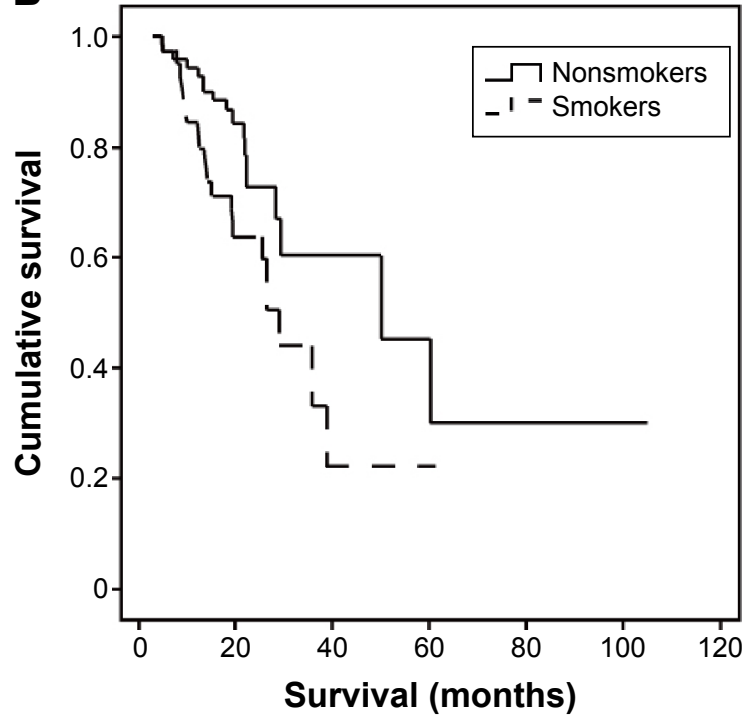

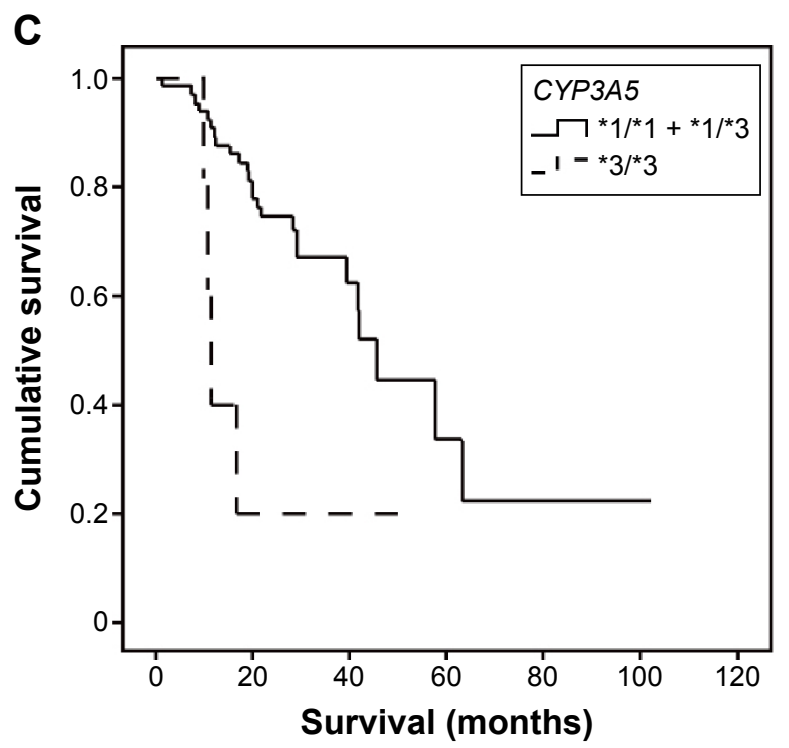

Figure 3 Risk factors of overall survival for non-small-cell lung cancer patients undergoing surgery.

Notes: $(\mathbf{A})$ Overall survival in different genotypes $(P=0.009) ;(B)$ overall survival in smoking and nonsmoking patients $(P=0.013)$; $(\mathbf{C})$ overall survival in different genotypes for smoking patients $(P=0.018)$.

(95\% CI 1.197-7.961, $P=0.020$ ). As shown in Figure 3B, smoking was also a risk factor for the patients undergoing surgery ( $P=0.013$ ), with a mortality risk 1.896 greater than nonsmoking (95\% CI 1.040-3.455, $P=0.037$ ). After smoking-stratification analysis for NSCLC patients undergoing surgery, smoking patients with $* 1 / * 1+* 1 / * 3$ has significantly longer overall survival than those with the $* 3 / * 3$ genotype, which showed statistical significance $(P=0.018)$ (Table 6 and Figure 3C).

Table 6 The association between the CYP3A5 rs776746 polymorphism and overall survival in the early non-small-cell lung cancer patients after surgery, by smoking-stratification analysis

\begin{tabular}{|c|c|c|c|c|c|c|}
\hline \multirow{2}{*}{$\begin{array}{l}\text { Stratification } \\
\text { factors }\end{array}$} & \multirow[t]{2}{*}{$\mathbf{n}$} & \multicolumn{2}{|c|}{ MST (months), mean (95\% CI) } & \multirow[t]{2}{*}{$P$-value } & \multirow[t]{2}{*}{ HR $(95 \% \mathrm{Cl})^{\mathrm{a}}$} & \multirow[t]{2}{*}{$P$-value ${ }^{a}$} \\
\hline & & $* \mathrm{I} / * \mathbf{I}+* \mathrm{I} / * 3$ & $* 3 / * 3$ & & & \\
\hline \multicolumn{7}{|l|}{ Smoking } \\
\hline Yes & 53 & $45.6(39.3-51.9)$ & II.4 (I0.I-I2.7) & 0.018 & $3.438(1.035-11.422)$ & 0.044 \\
\hline No & 51 & $63.1(38.3-87.9)$ & $57.6(37.5-77.7)$ & 0.423 & & \\
\hline
\end{tabular}

Note: adjustment for other clinical factors.

Abbreviations: MST, median survival time; $\mathrm{HR}$, hazard ratio; $\mathrm{Cl}$, confidence interval. 


\section{Discussion}

In the current study, the impact of the rs776746 polymorphism in the CYP3A5 gene and smoking on the prognosis of NSCLC was evaluated. Our results showed that the distribution frequencies of the $C Y P 3 A 5^{*} 3 / * 3$ genotype were $57.7 \%$ and $57.9 \%$ in NSCLC patients undergoing surgery and patients undergoing chemotherapy, respectively, suggesting that the $C Y P 3 A 5^{*} 3 / * 3$ genotype is possibly correlated with the development of NSCLC, which was consistent with Islam et al. ${ }^{22}$

One of our findings indicated that the $C Y P 3 A 5^{*} 3 / * 3$ genotype was a risk factor for survival for NSCLC patients undergoing surgery whose mortality risk was significantly greater than those with $* 1 / * 1+* 1 / * 3$, especially for smoking patients. The $C Y P 3 A 5^{*} 3$ (rs776746) polymorphism has a direct impact on CYP3A5 activity, and people are either functional expressers of CYP3A5, carrying at least one $C Y P 3 A 5^{*} 1$ allele, or are functional nonexpressers if they have the mutant allele of CYP3A5. ${ }^{23}$ The CYP3A5 enzyme is involved with the catalysis of oxidation for xenobiotic or exogenous carcinogens. ${ }^{13} * 1 / * 1+* 1 / * 3$ led to comparatively high levels of CYP3A5 expression, while the *3/*3 genotype was relevant to the loss of CYP3A5 expression, which may account for the accumulation of xenobiotics or endogenous steroids within various tissues. ${ }^{24}$ The mutant $C Y P 3 A 5^{*} 3 / * 3$ genotype reduced messenger RNA-expression levels and then decreased the activity of the CYP3A5 enzyme, resulting in drug toxicity as well as subsequent DNA damage. ${ }^{25}$ Tobacco smoke contains 70 kinds of exogenous carcinogens as substrates of CYP3A5, and may induce oxidation of xenobiotics, causing severe impairment to cellular macromolecules. ${ }^{26}$ However, with decreased CYP3A5 activity, the oxidation and biotransformation of carcinogens caused by smoking in vivo weakened, as reflected in our result that smoking was a risk factor for NSCLC patients undergoing surgery with a mortality risk 1.896 times greater than in nonsmoking patients. Parsons et al reported that exposure to tobacco triggers mutagenesis resulting in the progression of NSCLC, and constant smoking enhanced recurrence and mortality in the early stage of NSCLC patients. ${ }^{27}$

Another finding in our study was that the mutant homozygote $C Y P 3 A 5^{*} 3 / * 3$ genotype can reduce mortality risk and then increase overall survival for nonsmoking NSCLC patients undergoing paclitaxel-based chemotherapy. Paclitaxel is a cytotoxic agent that is currently available for the treatment of aggressive NSCLC, and its metabolism is largely mediated through CYP3A5, CYP3A4, and CYP2C8. ${ }^{28,29}$ The CYP3A5 genotype and expression levels of its protein play a significant role in the promotion of drug metabolism. ${ }^{30}$ As mentioned earlier, the $C Y P 3 A 5^{*} 3 / * 3$ genotype is correlated with enzyme-activity reduction, and enzyme activity may be merely half when compared with those carrying at least one wild-type allele $(* 1 / * 1+* 1 / * 3)$, thereby the metabolic rate of some drugs is lowered. ${ }^{31}$ In our study, for nonsmoking NSCLC patients undergoing chemotherapy, chemotherapy was more effective to those carrying with the $C Y P 3 A 5^{*} 3 / * 3$ genotype, due to their decreased paclitaxel metabolism. Leskelä et al also revealed the impact of the CYP3A5 polymorphism on the metabolism and pharmacokinetics of paclitaxel. ${ }^{32}$

It is concluded that the CYP3A5 rs776746 polymorphism and smoking may influence the prognosis of NSCLC patients undergoing chemotherapy and surgery. Our study demonstrated that the $* 1 / * 1+* 1 / * 3$ genotype in the CYP3A5 gene and smoking may contribute to worse prognoses for NSCLC patients undergoing chemotherapy, while the $* 3 / * 3$ genotype and smoking is likely to be a risk factor for survival in NSCLC patients undergoing surgery. Further study with a large population or from other populations investigating the functional CYP3A5 enzyme and the impact of $C Y P 3 A 5$ genetic polymorphism on the prognosis of NSCLC is needed to support our results.

\section{Acknowledgments}

This project was supported by the Experimental Study on the Apoptosis of Human Lung Adenocarcinoma Cell Line Induced by EGFR/ERK/Livin/Caspase-3 Pathway (2013022058). We would like to acknowledge the reviewers for their helpful comments on this paper.

\section{Disclosure}

The authors report no conflicts of interest in this work.

\section{References}

1. Lim JE, Kimm H, Jee SH. Combined effects of smoking and bilirubin levels on the risk of lung cancer in Korea: the Severance Cohort study. PLoS One. 2014;9(8):e103972.

2. Ferlay J, Shin HR, Bray F, Forman D, Mathers C, Parkin DM. Estimates of worldwide burden of cancer in 2008: Globocan 2008. Int J Cancer. 2010;127(12):2893-2917.

3. Jia Y, Zang A, Shang Y, et al. Microrna-146a rs2910164 polymorphism is associated with susceptibility to non-small cell lung cancer in the Chinese population. Med Oncol. 2014;31(10):194.

4. Merrow CE, Wang IZ, Podgorsak MB. A dosimetric evaluation of VMAT for the treatment of non-small cell lung cancer. J Appl Clin Med Phys. 2013;14(1):4110.

5. Alberg AJ, Brock MV, Ford JG, Samet JM, Spivack SD. Epidemiology of lung cancer: Diagnosis and management of lung cancer, 3rd ed: American College of Chest Physicians evidence-based clinical practice guidelines. Chest. 2013;143(5 Suppl):e1S-e29S. 
6. Torre LA, Bray F, Siegel RL, Ferlay J, Lortet-Tieulent J, Jemal A. Global cancer statistics, 2012. CA Cancer J Clin. 2015;65(2):87-108.

7. $\mathrm{Xu} \mathrm{J}$, Yin $\mathrm{Z}$, Gao W, et al. Genetic variation in a microrna-502 minding site in SET8 gene confers clinical outcome of non-small cell lung cancer in a Chinese population. PLoS One. 2013;8(10):e77024.

8. Quintans JS, Antoniolli AR, Onofre FM, Onofre AS. Detection of lung cancer using multiple genetic markers - a systematic review. Diagn Cytopathol. 2013;41(9):834-842.

9. Verhagen AF, Schoenmakers MC, Barendregt W, et al. Completeness of lung cancer surgery: is mediastinal dissection common practice? Eur J Cardiothorac Surg. 2012;41(4):834-838.

10. Yan PW, Huang XE, Yan F, Xu L, Jiang Y. Influence of MDR1 gene codon 3435 polymorphisms on outcome of platinum-based chemotherapy for advanced non small cell lung cancer. Asian Pac J Cancer Prev. 2011;12(9):2291-2294.

11. Wu H, Qiao N, Wang Y, et al. Association between the telomerase reverse transcriptase (TERT) rs2736098 polymorphism and cancer risk: evidence from a case-control study of non-small-cell lung cancer and a meta-analysis. PLoS One. 2013;8(11):e76372.

12. Lu Y, Hendrix CW, Bumpus NN. Cytochrome P450 3A5 plays a prominent role in the oxidative metabolism of the anti-human immunodeficiency virus drug maraviroc. Drug Metab Dispos. 2012;40(12): 2221-2230.

13. Walsky RL, Obach RS, Hyland R, et al. Selective mechanism-based inactivation of CYP3A4 by CYP3cide (PF-04981517) and its utility as an in vitro tool for delineating the relative roles of CYP3A4 versus CYP3A5 in the metabolism of drugs. Drug Metab Dispos. 2012;40(9): 1686-1697.

14. Seo T, Pahwa P, McDuffie HH, et al. Association between cytochrome P450 3A5 polymorphism and the lung function in Saskatchewan grain workers. Pharmacogenet Genomics. 2008;18(6):487-493.

15. Gellner K, Eiselt R, Hustert E, et al. Genomic organization of the human CYP3A locus: identification of a new, inducible CYP3A gene. Pharmacogenetics. 2001;11(2):111-121.

16. Polimanti R, Piacentini S, Manfellotto D, Fuciarelli M. Human genetic variation of CYP450 superfamily: analysis of functional diversity in worldwide populations. Pharmacogenomics. 2012;13(16): 1951-1960.

17. Wang BS, Liu Z, Xu WX, Sun SL. CYP3A5*3 polymorphism and cancer risk: a meta-analysis and meta-regression. Tumour Biol. 2013;34(4): 2357-2366.

18. Zhang JY, Wang Y, Prakash C. Xenobiotic-metabolizing enzymes in human lung. Curr Drug Metab. 2006;7(8):939-948.

19. Willrich MA, Hirata MH, Hirata RD. Statin regulation of CYP3A4 and CYP3A5 expression. Pharmacogenomics. 2009;10(6):1017-1024.
20. Holt GR. Declaration of Helsinki - the world's document of conscience and responsibility. South Med J. 2014;107(7):407.

21. Eisenhauer EA, Therasse P, Bogaerts J, et al. New response evaluation criteria in solid tumours: revised RECIST guideline (version 1.1). Eur $J$ Cancer. 2009;45(2):228-247.

22. Islam MS, Mostofa AG, Ahmed MU, Bin Sayeed MS, Hassan MR, Hasnat A. Association of CYP3A4, CYP3A5 polymorphisms with lung cancer risk in Bangladeshi population. Tumour Biol. 2014;35(2): 1671-1678.

23. Zanger UM, Schwab M. Cytochrome P450 enzymes in drug metabolism: regulation of gene expression, enzyme activities, and impact of genetic variation. Pharmacol Ther. 2013;138(1):103-141.

24. Sailaja K, Rao DN, Rao DR, Vishnupriya S. Analysis of CYP3A $5 * 3$ and CYP3A $5 * 6$ gene polymorphisms in Indian chronic myeloid leukemia patients. Asian Pac J Cancer Prev. 2010;11(3):781-784.

25. Bolbrinker J, Seeberg S, Schostak M, et al. CYP3A5 genotype-phenotype analysis in the human kidney reveals a strong site-specific expression of CYP3A5 in the proximal tubule in carriers of the CYP3A5*1 allele. Drug Metab Dispos. 2012;40(4):639-641.

26. Zhang W, Pal SK, Liu X, et al. Myeloid clusters are associated with a pro-metastatic environment and poor prognosis in smoking-related early stage non-small cell lung cancer. PLoS One. 2013;8(5):e65121.

27. Parsons A, Daley A, Begh R, et al. Influence of smoking cessation after diagnosis of early stage lung cancer on prognosis: systematic review of observational studies with meta-analysis. BMJ. 2010;340:b5569.

28. Chatterjee A, Chattopadhyay D, Chakrabarti G. Mir-17-5p downregulation contributes to paclitaxel resistance of lung cancer cells through altering Beclin1 expression. PLoS One. 2014;9(4):e95716.

29. Cianfrocca M, Lee S, Von Roenn J, et al. Pilot study evaluating the interaction between paclitaxel and protease inhibitors in patients with human immunodeficiency virus-associated Kaposi's sarcoma: an Eastern Cooperative Oncology Group (ECOG) and Aids Malignancy Consortium (AMC) trial. Cancer Chemother Pharmacol. 2011;68(4): $827-833$.

30. Shirasaka Y, Chang SY, Grubb MF, et al. Effect of CYP3A5 expression on the inhibition of CYP3A-catalyzed drug metabolism: impact on modeling CYP3A-mediated drug-drug interactions. Drug Metab Dispos. 2013;41(8):1566-1574.

31. Singh MS, Francis PA, Michael M. Tamoxifen, cytochrome P450 genes and breast cancer clinical outcomes. Breast. 2011;20(2):111-118.

32. Leskelä S, Jara C, Leandro-García LJ, et al. Polymorphisms in cytochromes $\mathrm{P} 4502 \mathrm{C} 8$ and $3 \mathrm{~A} 5$ are associated with paclitaxel neurotoxicity. Pharmacogenomics J. 2011;11(2):121-129.
OncoTargets and Therapy

\section{Publish your work in this journal}

OncoTargets and Therapy is an international, peer-reviewed, open access journal focusing on the pathological basis of all cancers, potential targets for therapy and treatment protocols employed to improve the management of cancer patients. The journal also focuses on the impact of management programs and new therapeutic agents and protocols on

\section{Dovepress}

patient perspectives such as quality of life, adherence and satisfaction. The manuscript management system is completely online and includes a very quick and fair peer-review system, which is all easy to use. Visit http://www.dovepress.com/testimonials.php to read real quotes from published authors. 